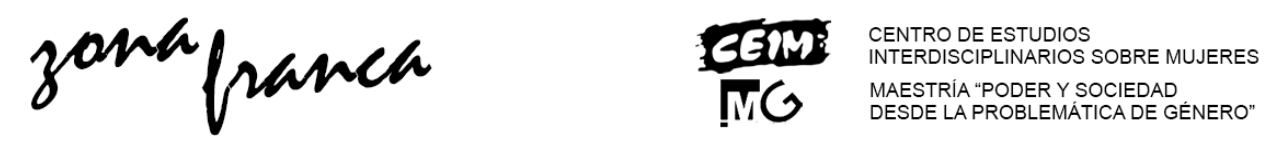

\title{
RECORDANDO A HILDA HABICHAYN, nuestra maestra
}

Pensar en Hilda Habichayn es pensar en aperturas, puentes y sentidos ligados al conocimiento. Para varias generaciones de investigadoras e investigadores sobre la situación de las mujeres, las relaciones de género y las teorías feministas su producción y su palabra fue una reconciliación con el conocimiento.

Fue docente en las Facultades de Psicología, de Ciencias Políticas y RRIl y de Humanidades y Artes. Su temprano interés por el estudio de la situación de las mujeres en nuestras sociedades, la llevó a investigar un abanico de problemáticas, desde la violencia doméstica, la maternidad, la prostitución, la salud, las sexualidades, la educación y socialización, el trabajo, el derecho y la política, publicando una vasta producción de artículos y libros a lo largo de su vida.

Junto a Héctor y un grupo de colegas de la escuela de Historia de nuestra facultad, que se interesaban por las mismas problemáticas, fueron pensando de qué manera hacer visibles sus investigaciones. Fue así que, en octubre de 1989, nace el Centro de Estudios Históricos Sobre las Mujeres (C.E.H.M.), radicado en la Escuela de Historia de la Facultad de Humanidades y Arte, luego denominado Centro de Estudios Interdisciplinarios sobre Mujeres (CEIM).

Ese mismo año concibe la Revista Zona Franca, una revista especializada en editar artículos sobre problemáticas de género en la que han publicado decenas de autoras y autores especializados en estas problemáticas. $Y$ aún, a 28 años de su 1er Número, se sigue editando.

En 1993 Hilda organiza la Maestría "Poder y sociedad desde la problemática de género" en nuestra Facultad de Humanidades y Artes. Fue su primera directora. Tuvo que sortear vicisitudes varias para abrirse camino, en sus propias palabras, dichas en el discurso de inauguración de la Maestría "En muchos momentos nos parecía que, como expresa Machado, era abrir caminos cuando "sólo hay estelas

Revista Zona Franca- Centro de estudios interdisciplinario sobre las mujeres (CEIM)- Maestría poder y sociedad desde la problemática de género (MG), Rosario, Argentina. ISSN, 2545-6504 http://zonafranca.unr.edu.ar/index.php/ZonaFranca| Número 29 (2021). 
en la mar..." En algunos momentos nos parecía estar pagando un derecho de piso $y$, en realidad fue así en el sentido de que la organización de estos estudios fue realmente crear algo de la nada, y equivocarnos muchas veces y tener que corregirnos, pero nos queda la satisfacción de saber que esto ya es una realidad...". Su sentido de pertenencia institucional hizo que no claudicara en la lucha por su total aprobación y legitimidad.

Supo rodearse de las mejores profesoras que dieron testimonio de sabiduría y pertinencia a la incipiente demanda de formación de cuarto nivel.

EI CEIM y la Maestría son las creaciones de Hilda. Cuando se retiró en el 2007 su amiga Elida Sonzogni escribió en su última editorial de Zona Franca “...no significa una despedida. Hilda ha dejado la honorabilidad del cargo, pero su genio no le impedirá mantener la misma preocupación y el mismo empeño de los que ha venido haciendo gala en todo el recorrido de estos casi 18 años pasados".

Hilda supo conquistar con creces el corazón de una legión de seguidoras que nunca olvidaran sus enseñanzas. Combatió con las mejores armas al patriarcado: creando el CEIM y la Maestría, con sus libros, artículos, conferencias, paneles, es decir con la palabra, los conceptos, la militancia. Su obra forma parte de la memoria de nuestra Facultad y de la UNR.

Ana Esther Koldorf*

\footnotetext{
* Centro de Estudios Interdisciplinarios sobre las Mujeres- Universidad Nacional de Rosario. Contacto: anaesther.koldorf@gmail.com
}

Revista Zona Franca- Centro de estudios interdisciplinario sobre las mujeres (CEIM)- Maestría poder y sociedad desde la problemática de género (MG), Rosario, Argentina. ISSN, 2545-6504 http://zonafranca.unr.edu.ar/index.php/ZonaFranca| Número 29 (2021). 